MATEC Web of Conferences 25, 04010 (2015)

DOI: $10.1051 /$ matecconf/ 20152504010

(C) Owned by the authors, published by EDP Sciences, 2015

\title{
Pilot Study on Carbon-sand Filter for Sedimentation Effluent
}

\author{
Shuo Zhang, Ruhua Wang \& Baoxiang Cai \\ Shanghai Municipal Engineering Design Institute (Group) Co., Ltd., Shanghai, China
}

\begin{abstract}
The development of dual function of integrating with activated carbon adsorption and quartz sand filtration in the carbon-sand filter can collaboratively remove organic matters and turbidity and also protect the bio-security, and the pilot test is carried out to optimize the process parameters. The pilot test results show that the thickness of the filter materials is preferably $1,300 \mathrm{~mm}$ of the activated carbon, $500 \mathrm{~mm}$ of uniform quartz sand; filtration rate can be $8-12 \mathrm{~m} / \mathrm{h}$; filter cycle is $24-48 \mathrm{~h}$; when the water temperature is $21^{\circ} \mathrm{C}$ to $29^{\circ} \mathrm{C}$, the biofilm formation period in the carbon-sand filter is 15 to 20 days; removal of the organic matters and nitrogen runs through the entire filter bed, and the nitrite is mainly oxidized on the upper side; when the operation is mature, the layer of filter materials can form the biofilm and zoogloea, with the dual function of micro-biological degradation and activated carbon adsorption.
\end{abstract}

Keywords: carbon-sand filter; sedimentation effluent; head loss; deep treatment

\section{INTRODUCTION}

Currently, the process of ozone-biological activated carbon is often placed after the sand filter so as to reduce the influent water turbidity of the carbon tank, prevent clogging micropores of the activated carbon, and give full play to the function of adsorption of organic matters by the activated carbon ${ }^{[1]}$. In recent years, the biosecurity of the filtered water of the activated carbon becomes a growing concern ${ }^{[2]}$. Therefore, in some projects, in the technological process, the sand filters or membrane filters are set up behind the activated carbon filter ${ }^{[3]}$ so as to control the water security. The establishment of the sand filters or membrane units may bring the following disadvantages: 1) larger investment, especially the membrane equipment and pneumatic valves; 2 ) the increase of the number of buildings, and occupation of land; 3 ) the demand of hydraulic power is promoted, and the energy consumption is significantly increased, especially the membrane.

In the design of carbon tank, the place below the carbon layer of the activated carbon adsorption tank is often equipped with a supporting layer at a layered level of gravel. Taking into account different specific gravities of activated carbon and quartz sand, the former is lighter than the latter. Therefore, there is a need of both organic bond to set up the sand layer below the carbon layer and above the supporting layer, set up reasonable grading and thickness, optimize backwash mode and strength, and develop a new integrated tank type with activated carbon adsorption-quartz sand filter, which has multiple synergies of catalytic oxidation, chemical and physical adsorption, biodegradation, intercepting filter and so on after integration with ozone, so as to achieve the goal of protecting bio-security, and avoiding the establishment of sand filters or membrane units, thereby significantly saving investment and reducing project sites. Through the pilot study, this paper researches startup of the carbon-sand filter, grading of filter material, filtration rate and so on, and sums up the characteristics of tank types.

\section{PILOT EXPERIMENT}

The pilot plant comprises a main filter unit and a contrast filter column. Process: to get water from the existing inlet channel of the water plant to the inlet tank, and lift to the main carbon-sand filter column $\left(20-25 \mathrm{~m}^{3} / \mathrm{h}\right)$ and comparative carbon-sand filter column $\left(3 \mathrm{~m}^{3} / \mathrm{h}\right)$, and effluent to flush and effluent tank. The influent water in the carbon-sand filter is sedimentation effluent with the turbidity of 1.2-2.8NTU, CODMn of about $2.5 \mathrm{mg} / \mathrm{L}, \mathrm{BOC}$ of about $2.5 \mathrm{mg} / \mathrm{L}$, and $\mathrm{NH}_{3}-\mathrm{N}$ of $0.2-0.5 \mathrm{mg} / \mathrm{L}$.

The height of the main filter column is $6.3 \mathrm{~m}$, and the diameter is DN1800. The area of the filter column is $2.54 \mathrm{~m}^{2}$, the filtration rate is $7.87-9.84 \mathrm{~m} / \mathrm{h}$, and the residence time of carbon bed adsorption is $9.9 \mathrm{~min}$.

The upper layer of the filter materials adopts the granular active carbon, of which the thickness of filter materials is $1.3 \mathrm{~m}$, the grain size is $8 \times 30, \mathrm{~d}_{10}=0.9 \mathrm{~mm}$, and the bulk density is $0.35-0.55 \mathrm{~g} / \mathrm{cm}^{3}$; the lower layer adopts homogeneous sand filter, of which the thickness is $0.50 \mathrm{~m}, \mathrm{~d}_{10}=0.5 \mathrm{~mm}, \mathrm{k}_{80} \leq 1.4$. It distributes water in a way of long handle filter head, and carries out backwash in a way of separate air impact and separate water wash: The air-impact strength is $55 \mathrm{~m}^{3} / \mathrm{m}^{2} \cdot \mathrm{h}$, and the water-washed strength is $25 \mathrm{~m}^{3} / \mathrm{m}^{2} \cdot \mathrm{h}$ (interim). The backwash period is about 2 to 3 days.

The height and layout of the comparative filter column is the same with that of the main filter column 


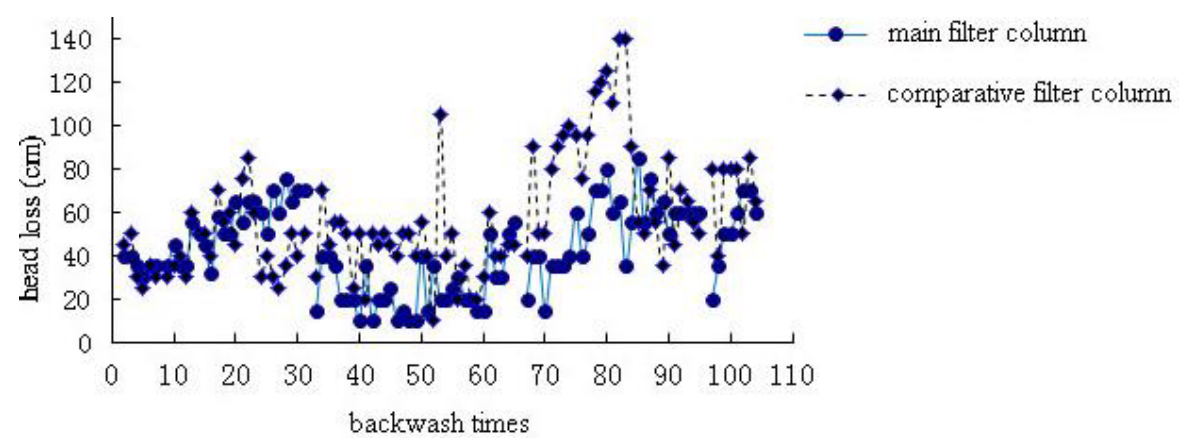

Figure 1. Filtering head loss of the main filter column and comparative filter column

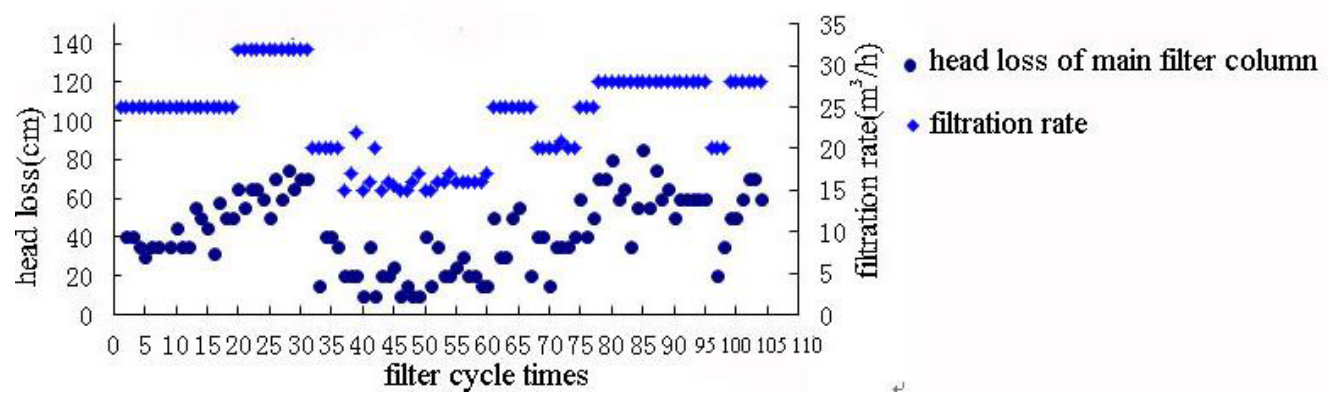

Figure 2. Head loss under different filtration rates

with the diameter of DN400. The residence time of carbon bed adsorption is $10.55 \mathrm{~min}$, and corresponding filtration rate is $7.96 \mathrm{~m} / \mathrm{h}$. The upper layer of the filter materials adopts the granular active carbon, of which the thickness of filter bed is $1.4 \mathrm{~m}$, the grain size is $8 \times$ 30 , and the bulk density is $0.35-0.55 \mathrm{~g} / \mathrm{cm}^{3}$; the sublayer of sand filter adopts homogeneous sand filter, of which the thickness of filter bed is $0.75 \mathrm{~m}$, $\mathrm{d}_{10}=0.60 \mathrm{~mm}, \mathrm{k}_{80} \leq 1.4$. It distributes water in a way of short handle filter head and carries out backwash in a way of separate air impact and separate water wash: The air-impact strength is $55 \mathrm{~m}^{3} / \mathrm{m}^{2} \cdot \mathrm{h}$, and the water-washed strength is $25 \mathrm{~m}^{3} / \mathrm{m}^{2} \cdot \mathrm{h}$.

3 IMPACT OF THE THICKNESS AND GRADING OF FILTER MATERIALS ON THE OPERATION AND TREATMENT EFFECT

Comparative analysis is given to the changes of the head loss of the main filter column and comparative filter column with the same filtration rate and filter cycle. The test results are shown in Figure 1. Comparative analysis is given to the changes of the head loss of the carbon-sand filter column under the condition of the same filter cycle and different filter flows, of which the filter cycle is $24 \mathrm{~h}$, and the filter flow is $15-32 \mathrm{~m}^{3} / \mathrm{h}$, and the test results are shown in Figure 2 .

As can be seen from Figure 1, in a 24-hour opera- tion cycle, the head loss of the carbon-sand filter column is less than $1 \mathrm{~m}$. Under the same operating conditions, the head loss of the main filter column is slightly less than that of the comparative filter column. As can be seen from Figure 2, the head loss is increased with the increase of the filtration rate, the filter cycle is up to $105 \mathrm{~h}$, and the maximum head loss is not more than $1 \mathrm{~m}$.

The results of the disturbance at the layer of filter materials and the expansion of filter materials due to the backwash show that with a certain intensity of back washing and for the main filter column, there is no disturbance of the mixed layer by the layer of filter materials; for the comparative filter column, there is a slight disturbance of the mixed layer by the layer of filter materials. With a predetermined intensity of back washing, there is a slight expansion at the layer of filter materials without carbon accident.

\section{COMPARISON OF THE EFFLUENT EFFECT OF TWO FILTER COLUMNS}

Analysis and comparison are given to the impact of thickness and grading of different filter materials on the effluent quality, turbidity, color and $\mathrm{NH}_{3}-\mathrm{N}$. The test results are shown in Figure 3 to Figure 5.

As can be seen from Figure 3 to Figure 5, in a parallel test, the selected thickness and grading of two 
EMME 2015

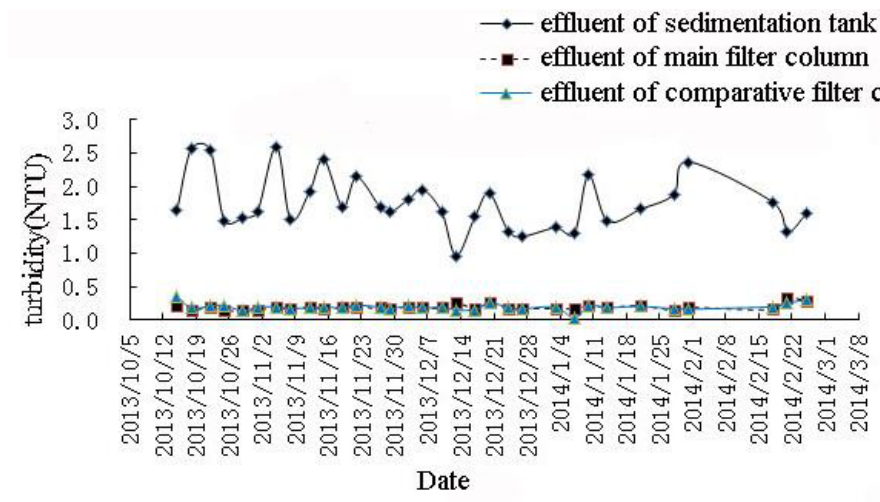

Figure 3. Removal of turbidity by the carbon-sand filter

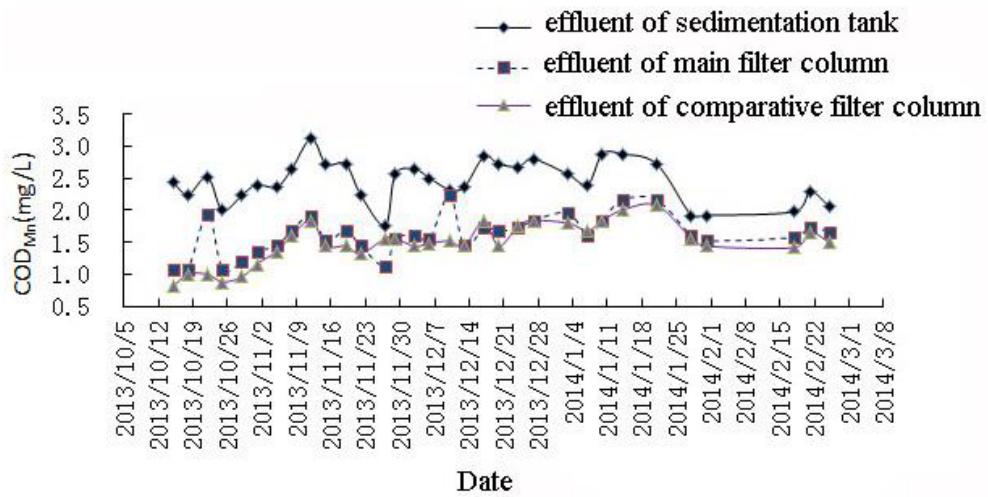

Figure 4. Removal of $\mathrm{COD}_{\mathrm{Mn}}$ by the carbon-sand filter

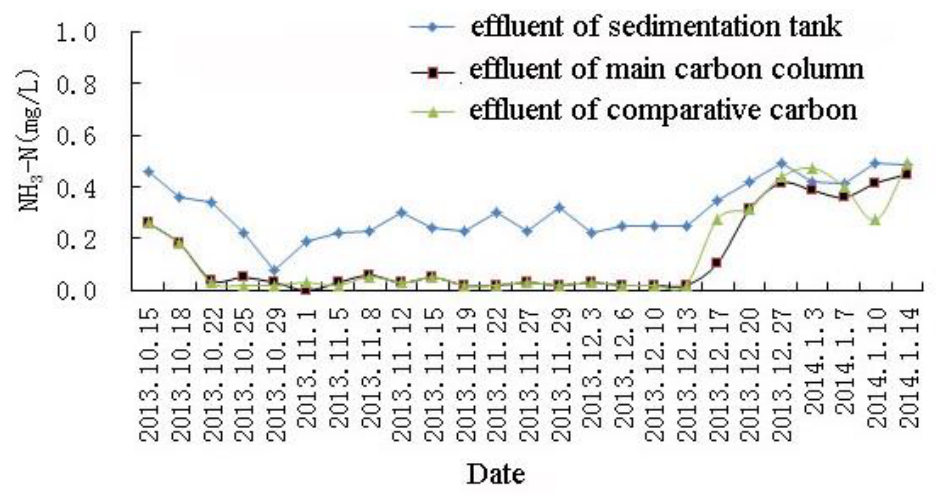

Figure 5. Removal of $\mathrm{NH}_{3}-\mathrm{N}$ by the carbon-sand filter

kinds of filter materials almost have the same effect on removing water contaminants without significant differences. The stable effluent turbidity is less than $0.5 \mathrm{NTU}$, the removal rate of $\mathrm{COD}_{\mathrm{Mn}}$ is above $30 \%$, the effluent $\mathrm{COD}_{\mathrm{Mn}}$ is less than $2.5 \mathrm{mg} / \mathrm{L}$, and the effluent $\mathrm{NH}_{3}-\mathrm{N}$ is close to $0 \mathrm{mg} / \mathrm{L}$ during high temperature period, but less than $0.5 \mathrm{mg} / \mathrm{L}$ during low temperature period.

\section{IMPACT OF THE FILTRATION RATE ON THE} REMOVAL OF TURBIDITY

The filter flow is $16-32 \mathrm{~m}^{3} / \mathrm{h}$, the filtration rate is $6.3-$ $12.6 \mathrm{~m} / \mathrm{h}$, the filter cycle is $24 \mathrm{~h}$, and there is a change of effluent turbidity of the main carbon-sand filter column. The test results are shown in Figure 6: 


\section{MATEC Web of Conferences}

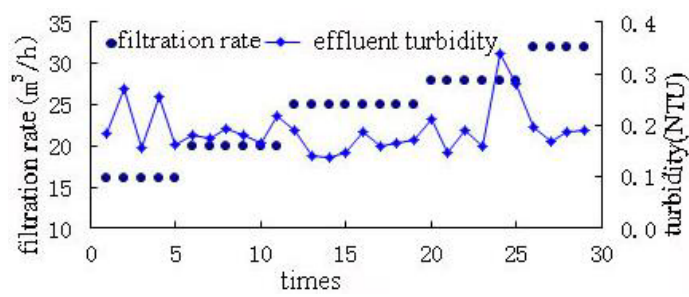

Figure 6. Impact of the filtration rate on the effluent turbidity

As can be seen from Figure 6, the change of the filtration rate does not have a significant impact on the effluent turbidity. The effluent turbidity value of the carbon-sand filter is changed between $0.15-0.35 \mathrm{NTU}$ without increasing or decreasing trend.

\section{IMPACT OF THE FILTRATION RATE ON THE REMOVAL OF COD $_{\mathrm{MN}}$ AND BOC}

After research and analysis, the filter flow is 16 $32 \mathrm{~m}^{3} / \mathrm{h}$, the filtration rate is $6.3-12.6 \mathrm{~m} / \mathrm{h}$, the filter cycle is $24 \mathrm{~h}$, and there is a change of effluent $\mathrm{COD}_{\mathrm{Mn}}$ and BOC of the main carbon-sand filter column. The test results are shown in Figure 7 and Figure 8.

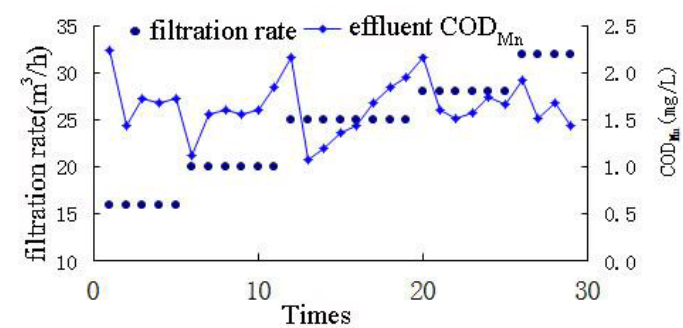

Figure 7. Impact of the filtration rate on effluent $\mathrm{COD}_{\mathrm{Mn}}$

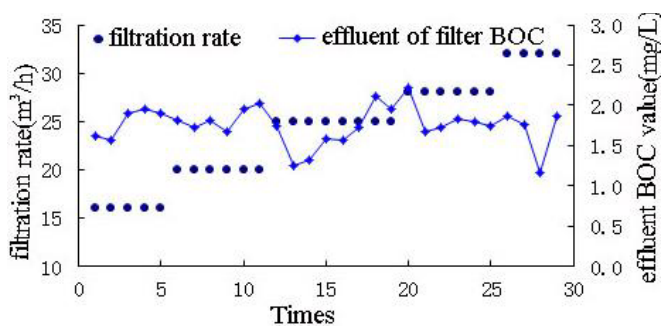

Figure 8. Impact of the filtration rate on effluent BOC

As can be seen from Figure 7 and Figure 8, the change of filtration rate does have a significant impact on the treatment effect of $\mathrm{COD}_{\mathrm{Mn}}$ and BOC, the effluent $\mathrm{COD}_{\mathrm{Mn}}$ of the carbon-sand filter is $1.25-2.25 \mathrm{mg} / \mathrm{L}$, and $\mathrm{BOC}$ is $1.0-2.0 \mathrm{mg} / \mathrm{L}$ without significant change trend.

\section{IMPACT OF THE FILTRATION RATE ON THE} REMOVAL OF NH3-N

After research and analysis, the filter flow is $16-32 \mathrm{~m}^{3} / \mathrm{h}$, the filtration rate is $6.3-12.6 \mathrm{~m} / \mathrm{h}$, the filter cycle is $24 \mathrm{~h}$, and there is a change of effluent $\mathrm{NH}_{3}-\mathrm{N}$ of the main carbon-sand filter column. The test results are shown in Figure 9:

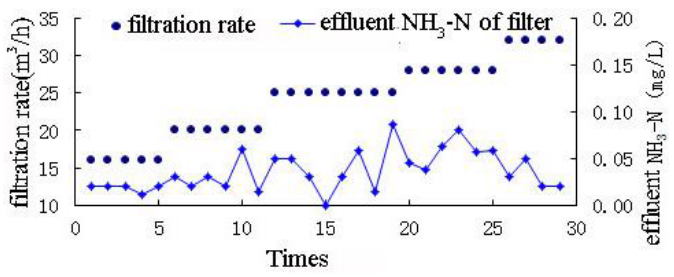

Figure 9. Impact of the filtration rate on effluent $\mathrm{NH}_{3}-\mathrm{N}$

As can be seen from Figure 9, the effluent NH3-N of the carbon-sand filter almost has no significant changes under different filtration rates, which is always $0.1 \mathrm{mg} / \mathrm{L}$ or less than that.

\section{IMPACT OF THE FILTRATION RATE ON THE REMOVAL OF $\mathrm{NO}_{2}-\mathrm{N}$}

After research and analysis, the filter flow is $16-32 \mathrm{~m}^{3} / \mathrm{h}$, the filtration rate is $6.3-12.6 \mathrm{~m} / \mathrm{h}$, the filter cycle is $24 \mathrm{~h}$, and there is a change of effluent $\mathrm{NO}_{2}-\mathrm{N}$ of the main carbon-sand filter column. The test results are shown in Figure 10:

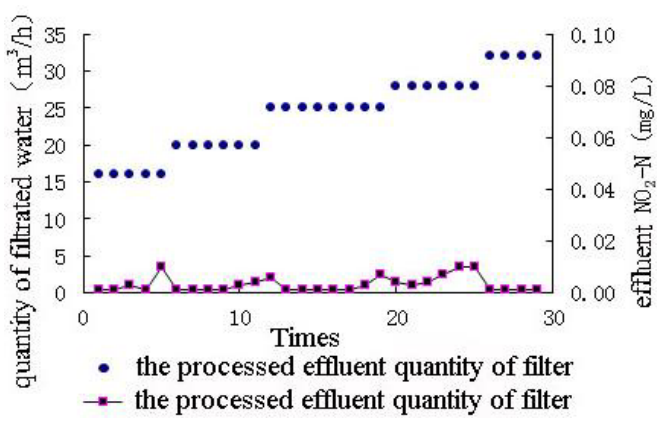

Figure 10. Impact of the filtration rate on effluent $\mathrm{NO}_{2}-\mathrm{N}$

As can be seen from Figure 10, the effluent $\mathrm{NO}_{2}-\mathrm{N}$ of the carbon-sand filter almost has no significant changes under different filtration rates, which is always $0.01 \mathrm{mg} / \mathrm{L}$ or less than that.

\section{REMOVAL OF CONTAMINANTS ALONG THE DEPTH OF LAYER OF FILTER MATE- RIALS}

The test respectively selects samples below the carbon 
EMME 2015

Table 1. Changes of water quality of carbon-sand filter column along the depth of filter bed

\begin{tabular}{|c|c|c|c|c|c|c|c|c|}
\hline \multirow{2}{*}{\multicolumn{2}{|c|}{ Water quality index }} & \multirow{3}{*}{$\begin{array}{l}\text { Sedimentation } \\
\text { effluent }\end{array}$} & \multicolumn{3}{|c|}{ Main filter column } & \multicolumn{3}{|c|}{ Comparative filter column } \\
\hline & & & \multirow{2}{*}{$\begin{array}{l}\begin{array}{l}\text { Upper } \\
\text { layer }\end{array} \\
0.858\end{array}$} & \multirow{2}{*}{$\begin{array}{l}\begin{array}{l}\text { Middle } \\
\text { layer }\end{array} \\
0.850\end{array}$} & \multirow{2}{*}{$\begin{array}{l}\begin{array}{l}\text { Lower } \\
\text { layer }\end{array} \\
0.120\end{array}$} & \multirow{2}{*}{$\begin{array}{l}\begin{array}{l}\text { Upper } \\
\text { layer }\end{array} \\
0.860\end{array}$} & \multirow{2}{*}{$\begin{array}{l}\begin{array}{l}\text { Middle } \\
\text { layer }\end{array} \\
0.840\end{array}$} & \multirow{2}{*}{$\begin{array}{l}\begin{array}{l}\text { Lower } \\
\text { layer }\end{array} \\
0.110\end{array}$} \\
\hline \multirow{3}{*}{$\begin{array}{l}\mathrm{NH}_{3}-\mathrm{N} \\
(\mathrm{mg} / \mathrm{L})\end{array}$} & $\begin{array}{l}\text { Maximum } \\
\text { value }\end{array}$ & & & & & & & \\
\hline & $\begin{array}{l}\text { Minimum } \\
\text { value }\end{array}$ & 0.080 & 0.040 & 0.050 & 0.020 & 0.080 & 0.030 & 0.020 \\
\hline & $\begin{array}{l}\text { Average } \\
\text { value }\end{array}$ & 0.374 & 0.370 & 0.351 & 0.033 & 0.371 & 0.332 & 0.043 \\
\hline \multirow{3}{*}{$\begin{array}{l}\mathrm{NO}_{2}-\mathrm{N} \\
(\mathrm{mg} / \mathrm{L})\end{array}$} & $\begin{array}{l}\text { Maximum } \\
\text { value }\end{array}$ & 0.162 & 0.033 & 0.006 & 0.011 & 0.090 & 0.029 & 0.001 \\
\hline & $\begin{array}{l}\text { Minimum } \\
\text { value }\end{array}$ & 0.024 & 0.001 & 0.001 & 0.001 & 0.004 & 0.001 & 0.001 \\
\hline & $\begin{array}{l}\text { Average } \\
\text { value }\end{array}$ & 0.079 & 0.007 & 0.002 & 0.004 & 0.022 & 0.006 & 0.001 \\
\hline \multirow{3}{*}{$\begin{array}{l}\mathrm{NO}_{3}-\mathrm{N} \\
(\mathrm{mg} / \mathrm{L})\end{array}$} & $\begin{array}{l}\text { Maximum } \\
\text { value }\end{array}$ & 3.61 & 3.56 & 3.58 & 3.63 & 3.60 & 3.63 & 2.65 \\
\hline & $\begin{array}{l}\text { Minimum } \\
\text { value }\end{array}$ & 1.76 & 2.10 & 2.14 & 2.19 & 2.02 & 2.15 & 2.37 \\
\hline & $\begin{array}{l}\text { Average } \\
\text { value }\end{array}$ & 2.16 & 2.57 & 2.60 & 2.68 & 2.53 & 2.60 & 2.50 \\
\hline \multirow{3}{*}{$\begin{array}{l}\mathrm{UV}_{254} \\
\left(\mathrm{~cm}^{-1}\right)\end{array}$} & $\begin{array}{l}\text { Maximum } \\
\text { value }\end{array}$ & 0.072 & 0.060 & 0.063 & 0.045 & 0.063 & 0.053 & 0.036 \\
\hline & $\begin{array}{l}\text { Minimum } \\
\text { value }\end{array}$ & 0.046 & 0.046 & 0.041 & 0.027 & 0.037 & 0.029 & 0.019 \\
\hline & $\begin{array}{l}\text { Average } \\
\text { value }\end{array}$ & 0.057 & 0.057 & 0.052 & 0.035 & 0.049 & 0.040 & 0.029 \\
\hline \multirow{3}{*}{$\begin{array}{l}\text { BOC } \\
(\mathrm{mg} / \mathrm{L})\end{array}$} & $\begin{array}{l}\text { Maximum } \\
\text { value }\end{array}$ & 3.86 & 2.46 & 2.23 & 2.05 & 2.33 & 2.22 & 1.74 \\
\hline & $\begin{array}{l}\text { Minimum } \\
\text { value }\end{array}$ & 1.96 & 1.47 & 1.33 & 1.10 & 1.30 & 1.22 & 0.93 \\
\hline & $\begin{array}{l}\text { Average } \\
\text { value }\end{array}$ & 2.52 & 2.05 & 1.90 & 1.66 & 1.96 & 1.86 & 1.50 \\
\hline
\end{tabular}

layer of $400 \mathrm{~mm}, 800 \mathrm{~mm}$ and $1,200 \mathrm{~mm}$. The changes of water quality indexes along the depth of filter bed are shown in Table 1.

As shown in Table 1, NH3-N has an obvious removal effect on each height of the activated carbon filter bed. The removal rate of $\mathrm{NO}_{2}-\mathrm{N}$ at the top of $400 \mathrm{~mm}$ is up to above $95 \%$, because the dissolved oxygen in the upper part is rich, which is conducive to the oxidation reaction. The nitrate continuously rises along the carbon layer, because the NH3-N and nitrite nitrogen will be converted to the nitrate. The organic indicators of $\mathrm{UV}_{254}$ and BOC are continuously declined along the carbon layer.

\section{COMPLETE WATER QUALITY ANALYSIS}

To further analyze the treatment effect of the overall process, water samples are selected from the processing unit (the effluent is disinfected).

The results show that the removal effect of the main carbon-sand filter column is good, and generally reaches the requirements of Drinking Water Sanitary Standards (GB5749-2006), so that the important indi- cators are obviously better than the limiting value of the indicators; under the effect of the activated carbon adsorption, $\mathrm{COD}_{\mathrm{Mn}}$ is $1.66 \mathrm{mg} / \mathrm{L}$, the removal rate is nearly $34 \%$, and the chroma is 5 degrees, which is only one-third of the national standard limit. After quartz sand filtration, the water turbidity is only $0.24 \mathrm{NTU}$, and the removal rate is over $90 \%$. After testing, the concentration of water bromate is less than $0.002 \mathrm{mg} / \mathrm{L}$ after delivery.

\section{CHARACTERISTICS OF CARBON-SAND FILTER}

The research and development, and pilot scale test shows that, the carbon-sand tank and its integration technology have the following characteristics:

(1) Multiple functions: With multiple synergies of catalytic oxidation, chemical and physical adsorption, biodegradation, intercepting filter and so on after integration, a single tank can effectively remove the organic matters, turbidity and fall off the biofilms. The particle size of the activated carbon is greater than the effective particle size of the quartz sand, so the acti- 


\section{MATEC Web of Conferences}

vated carbon is prone to play a role of adsorption, and prevent clogging, and give full play to the filtration of the underlying quartz sand, thereby improving the water quality by the use of multiple effects of the biological activated carbon, and protecting the bio-security.

(2) Resource conservation: After the activated carbon adsorption and quartz sand filtration, they are integrated into a single tank, so as to save the sand filter or membrane unit separately established for subsequent protection of the bio-security, avoid the hydraulic lifting, significantly reduce the construction land, and achieve the triple role of land saving, energy conservation and materials saving. The new carbon-sand tank, the combined sedimentation and the integrated process of deep treatment reduces once respectively, the hydraulic power will be advanced about $2.5-3 \mathrm{~m}^{[4]}$

(3) Efficient security: The structures integrated with multi-functions can achieve high-efficient removal of contaminants and play a role of functional complementation. After optimization of process parameters and operation mode, it can achieve the goal of long-term stable and reliable production, and simple management and maintenance.

(4) Investment saving: Compared with the process of sand filtration or membrane filtration added behind the activated carbon adsorption tank, the integrated carbon-sand process can avoid the establishment of sand filtration or membrane filtration due to the security function of the integration of biosecurity, thus saving a lot of equipment materials and engineering investment, shortening the construction period, and reducing operation and management costs. A total investment of the integrated process of carbon-sand deep treatment is only about 480 yuan $/ \mathrm{m}^{3}$, of which the engineering cost in the first part is 360 yuan $/ \mathrm{m}^{3}$, which saves up to $30 \%$ compared with the new process of ozone-activated carbon-sand filtration.

\section{CONCLUSIONS}

(1) When the filtration rate is $8-10 \mathrm{~m} / \mathrm{h}$, and the operation cycle is within 24 hours, the head loss of the carbon-sand filter column is less than $1 \mathrm{~m}$, which rises with the increase of treated water yield. When the filtration rate changes between $8 \mathrm{~m} / \mathrm{h}$ and $12 \mathrm{~m} / \mathrm{h}$, it will not cause a greater impact on the effluent quality of the filter, but a high flow rate may shorten the filter cycle

(2) The thickness and grading of two kinds of filter materials have a better effect on removing water contaminants and a considerable interception capability. Under the same operating conditions, the head loss of the main filter column is slightly less than that of the comparative filter column.

(3) When the water temperature is $21^{\circ} \mathrm{C}$ to $29^{\circ} \mathrm{C}$, the biofilm formation period in the carbon-sand filter is 15 to 20 days. After being mature, it may form biofilms and zoogloea within the layer of filter materials, and effectively remove $\mathrm{NH}_{3}-\mathrm{N}$ and organic matters through dual functions of the microbial degradation and activated carbon adsorption.

(4) Through the research and analysis of removing the contaminants along the elevation by the carbon-sand filter, the removal of the organic matters and nitrogen runs through the entire filter bed, and the nitrite conversion is mainly at the upper layer.

\section{ACKNOWLEDGEMENTS}

The authors would like to acknowledge the financial support by the key Special Program on the S\&T for the Pollution Control and Treatment of Water Bodies (No.2012ZX07403-003) and Shanghai Rising-Star Program (No.13QB1403300).

\section{REFERENCES}

[1] Kim K S, Oh B S, \& Kang J W. 2005. Effect of ozone and GAC process for the treatment of micropollutants and DBPs control in drinking water: pilot scale evaluation. Ozone-Science \& Engineering, 27(1):69-79.

[2] Van Lieverloo J H M, Bosboom D W, \& Bakker C L. 2004. Sampling and quantifying invertebrates from drinking water distribution mains. Water Research, 38(3): 1101-1112.

[3] Xu Jiajiong. 2012. System selection and application of biological activated carbon treatment. Water \& wastewater engineering, 38(9):33-37.

[4] Zhao Hui, \& Wang Ruhua. 2012. Joint Technological Processes of Ozone Activated Carbon and Membrane Filtration for Upgrading and Rehabilitation in Qingtai Waterworks. Water Purification Technology, 31(4):7-12. 